\title{
Case of endogenous endophthalmitis caused by Streptococcus equisimilis
}

This article was published in the following Dove Press journal:

Clinical Ophthalmology

II August 2010

Number of times this article has been viewed

\author{
Shinsuke Suemori' \\ Akira Sawada' \\ Shinya Komori' \\ Kiyofumi Mochizuki' \\ Kiyofumi Ohkusu ${ }^{2}$ \\ Hirofumi Takemura ${ }^{3}$ \\ 'Department of Ophthalmology, \\ ${ }^{2}$ Department of Microbiology, \\ ${ }^{3}$ Department of General and \\ Cardiothoracic Surgery Gifu \\ University Graduate School of \\ Medicine, Gifu, Japan
}

Correspondence: Akira Sawada

Gifu University Graduate School of

Medicine, I-I Yanagido, Gifu-shi

50I-I 194, Japan

Tel +8I 582305287

Fax +8I 582306289

Email sawadaa-gif@umin.ac.jp

\begin{abstract}
We report a rare case of endogenous endophthalmitis caused by Streptococcus equisimilis. A 74-year-old woman with endocarditis developed endogenous endophthalmitis. The patient underwent emergency mitral valvuloplasty, and intravitreal and subconjunctival injections of vancomycin and meropenem. After the surgery, she was treated with topical antibiotics, ointment, intravenous gentamicin and intravenous penicillin $\mathrm{G}$ potassium. The causative organism was identified as $S$. equisimilis. S. equisimilis should be considered as a pathogen that can cause severe endogenous endophthalmitis.
\end{abstract}

Keywords: endogenous endophthalmitis, group G Streptococcus, endocarditis, Streptococcus equisimilis

\section{Introduction}

Endogenous endophthalmitis is a rare and destructive disease that has a poor visual prognosis. The Lancefield group G beta-hemolytic streptococci (GGS) have been recognized as pathogens causing serious infections in humans, although GGS can have a commensal relationship when present on the skin, pharynx, intestinal tract, and vagina. ${ }^{1}$ The major pathological conditions predisposing GGS infections include malignancy, alcoholism, cardiovascular disease, diabetes mellitus, bone and joint diseases, and cirrhosis of the liver. We report a rare case of endogenous endophthalmitis caused by Streptococcus equisimilis, a GGS organism.

\section{Case report}

A 74-year-old woman became confused in her daily living, and the confusion was concomitant with a high-grade fever on April 29, 2008. She was admitted to a local hospital on the following day and was given intravenous ceftriaxone for 9 days. She had a history of cardiac and brain infarctions and was at the postoperative stage of uterine cancer. GGS was detected in cultures of her blood sample and she was suspected to have infective endocarditis. Although the hospital staff had noticed a moderate swelling of her left eyelid since May 1, 2008, an ophthalmologist did not examine her until she was referred to us on May 9, 2008.

Physical examination showed the patient to be a very ill woman with a body temperature of $38^{\circ} \mathrm{C}$. Her left eyelids were swollen, and a moderate degree of conjunctival infection with chemosis was observed in her left eye. Ophthalmic examination showed severe anterior chamber inflammation without hypopyon in her left eye. Her left fundus was not visible ophthalmoscopically due to hazy media. Ultrasonography of the posterior segment showed moderately dense infiltrations in the vitreous cavity. Her right eye was normal.

Auscultation of the heart revealed a III/VI systolic murmur at the apex. Transthoracic echocardiography disclosed a mobile mass associated with the mitral valve with moderate 


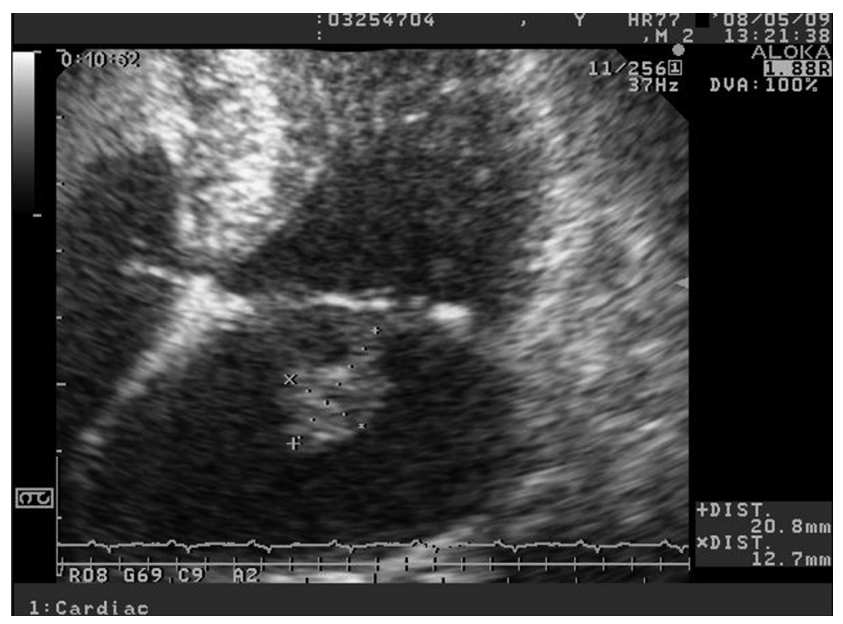

Figure I Preoperative transthoracic echocardiographic findings showing vegetation on the anterolateral commissure of the mitral valve.

valvular regurgitation (Figure 1). Laboratory tests demonstrated an elevated leucocyte count of $11850 / \mu \mathrm{L}$ with $82 \%$ of polymorphonuclear cells, a C-reactive protein level of $10.65 \mathrm{mg} / \mathrm{dL}$, lactate dehydrogenase level of $519 \mathrm{IU} / \mathrm{L}$, amylase level of $175 \mathrm{IU} / \mathrm{L}$, and brain natriuretic peptide level of $450.0 \mathrm{pg} / \mathrm{mL}$.

She was immediately hospitalized and on the same day (May 9, 2008) underwent emergency mitral valvuloplasty and both intravitreal and subconjunctival injections of both $1 \mathrm{mg} / \mathrm{mL}$ vancomycin and $1 \mathrm{mg} / \mathrm{mL}$ meropenem. After the surgery, she was treated with topical antibiotics (levofloxacin) and ointment (OFLX) for approximately 1 month, intravenous gentamicin ( $200 \mathrm{mg} /$ day), and intravenous penicillin $\mathrm{G}$ potassium $(240,000$ IU/day) for 9 days. Her general condition and ocular inflammation gradually improved with the medical therapy. However, her best-corrected visual acuity remained at light perception.

Subsequently, cultures from both anterior chamber and vitreous biopsy specimens grew $S$. equisimilis, which was sequenced by polymerase chain reaction. The $S$. equisimilis was found to be susceptible to penicillin G, ampicillin, sulbactam sodium/ampicillin sodium, imipenem/cilastatin, levofloxacin, and vancomycin, and was resistant to erythromycin and clarithromycin.

\section{Discussion}

S. dysgalactiae subsp. equisimilis hosts variants within the Lancefield group A, C, L, and G carbohydrates, and was

Clinical Ophthalmology

\section{Publish your work in this journal}

Clinical Ophthalmology is an international, peer-reviewed journal covering all subspecialties within ophthalmology. Key topics include: Optometry; Visual science; Pharmacology and drug therapy in eye diseases; Basic Sciences; Primary and Secondary eye care; Patient Safety and Quality of Care Improvements. This journal is indexed on recently determined by gene sequencing to be a subspecies of Group G of S. equisimilis. Exogenous GGS endophthalmitis has been reported following cataract surgery, penetrating keratoplasty and trabeculectomy. ${ }^{2}$ On the other hand, endogenous GGS-related endopthalmitis is extremely rare. ${ }^{1}$ So far, there have been only 8 cases of endogenous GGS-related endophthalmitis, ${ }^{3-5} 4$ cases associated with endocarditis, 1 with cellulites of the foot, 1 with facial trauma, 1 with an abscessed tooth, and 1 of unknown origin. In addition, S. equisimilis is of importance as causative bacteria of endocarditis. We demonstrated a case of an endogenous GGS-related endophthalmitis where $S$. equisimilis was first identified from both anterior chamber and vitreous biopsies, and where identification was also first made by polymerase chain reaction.

The first-line therapy of $S$. equisimilis-induced infections is penicillin. Besides penicillin, S. equisimilis has also been shown to be sensitive to cephem and carbapenem antibiotics. S. equisimilis was sensitive to all of the antimicrobial agents we administered. In our case, we suggest that a delay in the diagnosis would have worsened the general conditions of the patient, and would then lead to a poorer prognosis. At present, the efficacy of immediate ocular therapies including vitrectomy and intravitreal antibiotics against GGS-related endogenous endophthalmitis is still controversial. ${ }^{3}$ Only further investigations will answer this question.

\section{Disclosure}

The authors have no proprietary or financial interest in any products used in this study.

\section{References}

1. Auckenthaler R, Hermans PE, Washington JA 2nd. Group G streptococcal bacteremia: clinical study and review of the literature. Rev Infect Dis. 1983;5(2):196-204.

2. Goh ES, Liew GC. Traumatic bleb-associated Group-G beta-haemolytic Streptococcus endophthalmitis. Clin Experiment Ophthalmol. 2008; 36(6):580-581.

3. Tan JH, Newman DK, Burton RL. Endogenous endophthalmitis due to group G streptococcus. Eye. 1999;13(Pt 1):116-117.

4. Ziakas NG, Tzetzi D, Boboridis K, Georgiadis NS. Endogenous group G Streptococcus endophthalmitis following a dental procedure. Eur $J$ Ophthalmol. 2004;14(1):59-60.

5. Gopalamurugan AB, Wheatcroft S, Hunter P, Thomas MR. Bilateral endophthalmitis and ARDS complicating group G streptococcal endocarditis. Lancet. 2005;366(9502):2062.

\section{Dovepress}

PubMed Central and CAS, and is the official journal of The Society of Clinical Ophthalmology (SCO). The manuscript management system is completely online and includes a very quick and fair peer-review system, which is all easy to use. Visit http://www.dovepress.com/ testimonials.php to read real quotes from published authors. 